\title{
QUAL FORMA VOCÊ COSTUMA USAR PARA SE DIRIGIR A UM AMIGO?A ESCOLHA DE TRATAMENTO NAS RELAÇÕES SIMÉTRICAS EM FLORIANÓPOLIS/SC
}

\author{
WHICH FORM DO YOU USUALLY USE TO ADDRESS A FRIEND? THE CHOICE OF \\ THE FORM OF ADDRESS WITHIN SYMMETRIC RELATIONSHIPS IN \\ FLORIANOPOLIS/SC
}

\section{Patrícia Graciela da Rocha}

Professora da Universidade Federal do Mato Grosso do Sul patrigraciro@gmail.com

\begin{abstract}
RESUMO: Neste estudo, temos o objetivo de verificar qual é o pronome de segunda pessoa que os florianopolitanos afirmam usar para se dirigirem a seus pares nas relações simétricas, ou seja, na interação com amigos, amigas, irmãos, irmãs etc. Nosso aparato teórico e metodológico baseia-se nos pressupostos da Teoria da Variação e Mudança Linguística (WEINREICH, LABOV E HERZOG, 1968; LABOV, 1972, 1994). A amostra utilizada neste trabalho resulta de testes de percepção e de produção realizados na cidade de FlorianópolisSC. Os resultados apontam que, nas relações de simetria, os informantes garantem usar majoritariamente o $t u$, seguido por um baixo percentual de você e também por um baixo percentual de uso alternado das duas formas ( $t u$ e você). Esses resultados corroboram os de outras pesquisas com dados empíricos realizados em Florianópolis.
\end{abstract}

PALAVRAS-CHAVE: Pronomes. Segunda pessoa. Florianópolis. Sociolinguística. Relações simétricas.

ABSTRACT: In this paper, we aim at verifying, through perception and linguistic production tests, which second person pronoun people from Florianopolis affirm to use in order to communicate with their pairs in symmetrical relationships, like interactions with friends, siblings etc. The theoretical and methodological apparatuses are based on the Language Change and Variation Theory (WEINREICH, LABOV E HERZOG, 1968; LABOV, 1972, 1994). The sample used in this paper concerns production and perception tests realized in Florianópolis (SC) city. The findings point out that, in the symmetrical relationships, the informants ensure to use tu mostly followed by a low percentage of você as well as a low percentage of the alternated use of these two forms (tu and você). These results reaffirm other researches with empiric data realized in Florianópolis.

KEYWORDS: Pronouns. second person. Florianópolis. Sociolinguistics. symmetrical relationships.

\section{INTRODUÇÃO}

A escolha da forma pronominal que usamos para nos dirigir a um interlocutor qualquer, referido como segunda pessoa do discurso, pode parecer muito simples e sem grandes conflitos para a maioria das pessoas, isso porque não é comum pararmos para pensar sobre o motivo que nos leva a usar a forma "x" e não a forma " $y$ ". 
Sob o quadro teórico da Sociolinguística Quantitativa ou Teoria da Variação e Mudança, temos visto várias pesquisas que vêm apresentando resultados esclarecedores sobre os usos dos pronomes de segunda pessoa do discurso no português do Brasil. Nesse sentido, a Região Sul tem sido contemplada com muitos trabalhos que nos trazem uma boa descrição do fenômeno (RAMOS, 1989; SOARES, 1999; MENON, 2000; LEÃO, 2003; LOREGIANPENKAL, 2004; ARDUIN, 2005; COELHO E GÖRSKI, 2011; NUNES de SOUZA, 2011; ROCHA, 2012, dentre outros).

Este estudo parte dos resultados de uma pesquisa mais ampla (ROCHA, 2012) sobre o fenômeno da variação pronominal de segunda pessoa do singular, tu/vocêlo senhor, na função de sujeito e sua correlação com as formas pronominais que aparecem na função de complementos verbais e de adjuntos (oblíquos e possessivos) realizada a partir de dados sincrônicos do português brasileiro usado na cidade de Florianópolis - Santa Catarina Brasil. Nosso objetivo aqui é verificar, a partir de testes de percepção linguística, qual é o pronome de segunda pessoa que os florianopolitanos afirmam usar em situações de simetria na sua relação com os amigos, irmãos, pessoas mais íntimas etc.- e quais fatores estão envolvidos nessa escolha e, ao mesmo tempo, a partir dos testes de produção linguística, averiguar se os dados empíricos vão ao encontro da percepção que os sujeitos têm acerca dos seus próprios usos das formas pronominais de segunda pessoa do discurso.

\section{METODOLOGIA}

Nossa metodologia baseia-se nos pressupostos da Teoria da Variação e Mudança Linguística (WEINREICH, LABOV E HERZOG, 1968; LABOV, 1972, 1994) e a amostra utilizada nesta pesquisa compreende testes de percepção e de produção linguística que foram aplicados pela própria pesquisadora em escolas de Educação Básica, na Universidade Federal de Santa Catarina, no Instituto Federal de Santa Catariana, nas ruas e em alguns estabelecimentos comerciais de Florianópolis. Os testes aplicados na Universidade (UFSC) contaram com a ajuda de alguns professores da instituição que receberam orientação sobre como proceder.

Após a entrega dos testes impressos, realizou-se a leitura dos comandos, com a orientação de que os participantes não conversassem entre si e de que as dúvidas devessem ser esclarecidas pela pesquisadora ou, em alguns casos, pelo professor que estava aplicando o teste ${ }^{1}$.

Considerando que os alunos da Educação Básica tendem a tomar a pesquisa de opinião como uma avaliação, enfatizamos o objetivo da pesquisa, com a indicação de não haver uma resposta certa ou errada. Procuramos também deixar os participantes à vontade afirmandolhes que os testes não seriam vistos por seus professores.

Para a estratificação dos informantes, consideramos as seguintes variáveis extralinguísticas: sexo, idade e escolaridade, adotando o perfil descrito no quadro 1.

\footnotetext{
${ }^{1}$ Os testes podem ser visualizados na íntegra em Rocha (2012).
} 


\begin{tabular}{c|l|l|l|l}
\hline Sexo & $\begin{array}{l}\text { Informante } \\
1 \text { a } 10\end{array}$ & $\begin{array}{l}\text { Informante } \\
11 \text { a } 20\end{array}$ & $\begin{array}{l}\text { Informante } \\
21 \text { a } 30\end{array}$ & $\begin{array}{l}\text { Informante } \\
31 \text { a } 40\end{array}$ \\
\hline Feminino & $\begin{array}{l}12 \text { a } 33 \\
\text { anos. } \\
\text { Ensino } \\
\text { Fund. }\end{array}$ & $\begin{array}{l}17 \text { a } 33 \\
\text { anos. } \\
\text { Ensino } \\
\text { Superior }\end{array}$ & $\begin{array}{l}42 \text { a } 74 \\
\text { anos. } \\
\text { Ensino } \\
\text { Fund. }\end{array}$ & $\begin{array}{l}42 \text { a } 75 \\
\text { anos. } \\
\text { Ensino } \\
\text { Superior }\end{array}$ \\
\hline Masculino & $\begin{array}{l}12 \text { a 33 } \\
\text { anos. } \\
\text { Ensino } \\
\text { Fund. }\end{array}$ & $\begin{array}{l}17 \text { a 33 } \\
\text { Ensino } \\
\text { Superior }\end{array}$ & $\begin{array}{l}42 \text { a } 74 \\
\text { anos. } \\
\text { Ensino } \\
\text { Fund. }\end{array}$ & $\begin{array}{l}42 \text { a 75 } \\
\text { anos. } \\
\text { Ensino } \\
\text { Superior }\end{array}$ \\
\hline TOTAL & 10 & 10 & 10 & 10 \\
\hline
\end{tabular}

Quadro 1:Estratificação dos informantes dos testes

Quando aplicamos os testes nas salas de aula, seja na Educação Básica, seja no Ensino Superior, todos os alunos puderam participar e todos os testes foram recolhidos. Somente depois da coleta realizada é que fizemos a separação de acordo com as células sociais descritas no quadro anterior, e os que não faziam parte do perfil desejado foram, em um segundo momento, excluídos da amostra² ${ }^{2}$.

No teste de percepção fizemos as seguintes perguntas: (1) Qual forma você costuma usar para se dirigir a um amigo ou a uma amiga? (2) Qual forma você costuma usar para se dirigir ao seu pai ou a sua mãe? (3) Qual forma você costuma usar para se dirigir a alguém superior (chefe, por ex.)? (4) Qual dessas formas você acha boa ou mais bonita? e (5) Qual dessas formas você acha feia ou ruim? Em todas as perguntas o informante tinha três possibilidades de resposta objetiva: (a) Tu, (b) Você e (c) Senhor(a). Nas perguntas (4) e (5) havia ainda a alternativa de assinalar (d) Não acho feia ou ruim nenhuma das formas acima. $\mathrm{O}$ informante poderia também assinalar mais de uma alternativa, caso achasse necessário.

Neste trabalho, discutiremos apenas as respostas dadas à pergunta (1): Qual forma você costuma usar para se dirigir a um amigo ou a uma amiga?

No teste de produção ${ }^{3}$ os informantes tinham que preencher as lacunas com os pronomes que achassem mais adequados. Assim, tínhamos comandos do seguinte tipo: Imagine que você esteja convidando uma amiga ou um amigo para uma festa e quer saber se ela(ele) levará o(a) namorado(a). Então, como você diria? Diante de tal pergunta o sujeito deveria assinalar uma das opções e preencher uma lacuna como no exemplo ${ }^{4}$ :

\footnotetext{
( x ) tu vai(s) à(na) festa de hoje com o(a)_teu_namorado(a)?

( ) você vai à(na) festa de hoje com o(a) namorado(a)?
}

\footnotetext{
${ }^{2}$ Em Rocha (2012) podemos verificar que todos esses testes também foram considerados para uma explanação geral dos resultados.

${ }^{3} \mathrm{O}$ teste de percepção era realizado juntamente com o de produção, em uma única folha de papel, ou seja, de um lado estava o teste de percepção e do outro lado estava o teste de produção.

${ }^{4}$ Para ver teste completo, remetemos o leitor a Rocha (2012).
} 

namorado(a)?

Alcançamos, no total, 212 questionários respondidos, sendo 127 deles de informantes nascidos em Florianópolis ou região metropolitana e moradores desses mesmos lugares e 85 de informantes nascidos em outras cidades e moradores de Florianópolis ou região.

É importante dizer que, dentre os informantes de outras cidades, a maioria (63) é da Região Sul, sendo 26 do Rio Grande do Sul, 25 de Santa Catarina (exceto da região metropolitana) e 12 do Paraná. Os demais informantes são da Região Sudeste ( 7 de Minas Gerais, 6 de São Paulo, 4 do Rio de Janeiro), da Região Norte (2 do Maranhão), do CentroOeste (1 Mato Grosso do Sul) e do Nordeste (1 da Bahia). Além disso, tivemos 1 informante do Uruguai.

Podemos observar também que esse número de informantes de outras cidades (estados) reflete o fluxo de migração em Florianópolis, pois trata-se de uma cidade turística que recebe, todos os anos, milhares de visitantes, dentre os quais, muitos optam por voltar e morar na cidade. Além disso, a ilha e a região metropolitana comportam muitas universidades, institutos e escolas técnicas públicas e privadas, o que acaba atraindo também muitos estudantes vindos do interior do estado de Santa Catarina e também dos outros estados do país.

Depois dessa coleta de dados inicial, separamos os 127 testes respondidos por sujeitos nascidos em Florianópolis ou região metropolitana (São José, Palhoça, Biguaçu etc.) e, em seguida, usamos para análise apenas 40 testes ( 5 de cada célula social) que se encaixavam no perfil pré-estabelecido e descrito no quadro 1. Por fim, para os testes de percepção aplicamos a regra de três, chegamos aos percentuais de cada resposta e de cada variável que são apresentados em forma de gráfico no decorrer deste estudo. Para os testes de produção linguística, categorizamos os dados e os submetemos às rodadas estatísticas do programa Goldvarb (2001), realizando análises unidimensionais, considerando a alternância entre os pronomes $t u$, você e $o$ senhor, e multidimensionais considerando somente a alternância entre os pronomes tu e você. Nessas rodadas, controlamos os seguintes grupos de fatores linguísticos e extralinguísticos: (i) paralelismo sujeito e clítico; (ii) paralelismo sujeito e possessivo; (iii) preenchimento do sujeito;(iv) paralelismo sujeito e oblíquo tônico;(v) sexo; (vi) faixa etária; (vii) escolaridade e (viii) tipo de relação entre os interlocutores.

\section{REFERENCIAL TEÓRICO E REVISÃO DE LITERATURA}

A abordagem teórica deste estudo leva em conta os pressupostos da Teoria da Variação e Mudança Linguística (WEINREICH, LABOV e HERZOG, 1968; LABOV, 1972, 1994) e de autores que se debruçam sobre o estudo dos pronomes (BROWN e GILMAN, 1960, 2003).

A teoria da Variação e Mudança linguística (ou sociolinguística variacionista), proposta por Weinreich, Labov e Herzog $(2006 \text { [1968] })^{5}$, parte da premissa segundo a qual a heterogeneidade e a variabilidade são características inerentes à língua. Esta proposta rompe com a ideia, dominante na primeira metade do século XX, de que a língua é um sistema homogêneo, uniforme, estático, sistema de signos bem definidos, hierarquizados e sem variações.

\footnotetext{
${ }^{5}$ Versão utilizada: tradução de Marcos Bagno (2006).
} 
Para Weinreich, Labov e Herzog (2006 [1968]), a variação é inerente ao sistema linguístico, sistemática, regular e ordenada, sendo motivada por pressões sociais que estão permanentemente atuando na língua, e por isso não deve ser estudada fora do contexto social (LABOV, 2008 [1972] $)^{6}$.

Dentre as tarefas que a sociolinguística se propõe a realizar está o estudo das atitudes linguísticas que estão relacionadas ao problema da avaliação e dizem respeito aos julgamentos subjetivos do falante quanto à sua própria variedade linguística e a dos seus interlocutores.

O problema da avaliação linguística diz respeito a qualquer nível de atenção dos falantes em relação à fala e busca compreender de que maneira os membros de uma comunidade de fala avaliam determinada mudança, qual o efeito que essa avaliação provoca na mudança e até que ponto o estigma social influencia diretamente o curso da mudança linguística.

Uma das aspirações da investigação da avaliação linguística é a observação das respostas e reações subjetivas dos membros da comunidade diante de uma determinada mudança em curso. Essas respostas e reações perpassam todos os níveis de consciência, desde a discussão manifestada explicitamente até aquelas reações inacessíveis à introspecção. A maior parte dos estudos trata de reações manifestadas diante de mudanças que alcançam um certo nível de atenção consciente e tais reações tendem a ser negativas.

Para Labov (1972), os valores sociais atribuídos a duas formas linguísticas, uma padrão ou conservadora e outra inovadora, frequentemente simbolizam também uma oposição entre valores sociais. Esses valores sociais podem alcançar o nível de conscientização social e se tornarem estereótipos, sujeitos à correção social irregular ou, então, podem permanecer abaixo do nível consciente como marcadores inconscientes. Mas em estágios mais avançados, uma das formas vai prevalecer, embora nem sempre uma forma tida como inovadora vence, ou seja, a sua concorrente conservadora pode vencer o "duelo" instaurando-se, assim, um movimento de retração (mudança regressiva) e não de avanço (mudança progressiva). Seguese um longo período quando a forma desaparecida é usada como fonte de estereótipo até ser completamente extinta. Se a antiga pronúncia, por exemplo, é preservada em topônimos ou formas fixas, é ouvida como uma irregularidade sem sentido. Mas é possível também que a forma antiga sobreviva com outra função, ou seja, com especialização de uso.

É importante distinguir, no problema da avaliação social atribuído a formas ou variantes linguísticas, os diferentes estágios de mudança, pois a variação ocorre tanto no indivíduo como na comunidade. Sendo assim, é possível verificarmos diversos tipos de mudança: (i) mudança implementada - estágio mais adiantado em vias de implementação; (ii) estágios de taxa média e (iii) mudança incipiente - ainda pouco detectada. No nível estrutural, ocorre uma difusão através do sistema linguístico, em que o uso de uma forma ou variante parte de contextos mais restritos e vai atingindo contextos mais amplos com o decorrer do tempo. Em síntese, ocorre uma luta evolutiva entre as formas novas e as antigas, com as novas se espalhando tanto de um falante para outro como de um contexto linguístico para outro.

A mudança linguística pode ser impulsionada pelo prestígio das formas alternantes (variantes) e pode se encontrar em diferentes estágios de propagação. Porém, nem sempre uma das variantes é menos prestigiada do que outra, isto é, a variação pode ocorrer tanto entre: (i) formas igualmente aceitas pela tradição normativa, ii) formas de status normativo

\footnotetext{
${ }^{6}$ Versão utilizada: tradução de Marcos Bagno, Ma Marta Pereira Scherre e Caroline R. Cardoso (2008).
} 
desigual e iii) formas igualmente não aceitas normativamente. Fatores atuantes como a escolarização, contato com escrita, mídia e origem social tendem a influenciar no aumento ou na diminuição da ocorrência de formas padrões ou conservadoras.

No caso do nosso objeto de estudo, nesta pesquisa, acreditamos que não há um prestígio social generalizado por parte da sociedade florianopolitana, mas uma marca de identidade local. Trata-se da noção de prestígio encoberto, postulada por Labov (1972), que está associada à noção da identidade social, ao orgulho linguístico, à ligação a uma dada classe social ou comunidade de fala. Além disso, podemos sugerir que o você, embora ainda não seja reconhecido como pronome pessoal de segunda pessoa pela gramática normativa, é muito disseminado pela mídia escrita e televisiva de massa, o que contribui grandemente para que a forma não sofra estigma mesmo entre os falantes que não a usam. Entretanto, é possível que o $t u$ sofra estigma entre os falantes de outras regiões do país (não usuários de $t u$ ), pelo fato de ser uma forma utilizada somente em algumas regiões do Brasil e por não ser muito disseminado pela grande mídia.

Mollica (1995) sugere a existência de leis gerais e universais regulando a variação de uso da língua e de diferentes graus de percepção/avaliação passíveis de serem dimensionados pelo uso, sensibilidade e valor social dos fatos da língua. A autora adverte que alguns estudos empíricos atestam uma equivalência entre perfil sociolinguístico, crenças e atitudes linguísticas, e confirmam o efeito da escolarização, da pressão escolar e da idade como parâmetros sociais determinantes nas escolhas linguísticas dos indivíduos. Para a autora, esses parâmetros, a depender do fenômeno variável em foco, costumam agir imbricadamente.

Uma das evidências mais relevantes do trabalho de Mollica é a constatação da relação entre grau de percepção e valor social, ou seja, quanto menos notada ou percebida for uma variante, menor é o grau de estigmatização a ela atribuído. Em geral, formas que adquirem maior valor no mercado linguístico, e recebem assim avaliação positiva, tendem a ser usadas com um alto grau de monitoramento por parte do falante e por pessoas, geralmente, mais letradas.

A autora menciona também que a pressão social não promove somente variantes padrões, isto é, existem também contrapressões que prestigiam o uso da fala informal e vernacular.

Para Chambers (1995), as forças que prestigiam a variante padrão, ou standard, são mais claras e identificáveis: (i) a academia e as gramáticas tradicionais que invalidam usos mais coloquiais ou não abonados; (ii) os pais de classe média que defendem uma 'boa linguagem'; (iii) os professores que corrigem o uso dos alunos; (iv) as cartas ao editor que deploram usos não prescritos pela gramática normativa; (v) o falante que se desculpa pelo seu modo de falar 'errado' ou por cometer erros de ortografia ou de gramática; (vi) a não reclamação da hipercorreção na mídia ou da uniformidade de sotaque entre locutores de telejornais, dentre outras.

Para tratarmos do nosso objeto de estudo, fazemos uso da semântica do poder e semântica da solidariedade proposta por Brown e Gilman (1960). Com base no conceito desses dois termos, os autores analisam as diferenças existentes no uso de tais pronomes no francês, no alemão e no italiano. A análise parte dos pronomes latinos tu e vos. O primeiro, usado como pronome de familiaridade, recebeu designação geral de $T$ e o segundo, como pronome de formalidade, recebeu $V$. Estas duas letras foram usadas para representar esses dois conceitos gerais em qualquer língua. 
De acordo com esses autores, uma pessoa tem poder sobre outra conforme o grau em que ela é capaz de controlar o comportamento da outra. Porém, esse poder é não recíproco, pois em um relacionamento entre pelo menos duas pessoas, elas não podem ter poder na mesma área de comportamento. Sendo assim, a semântica de poder é não recíproca e, por isso, o superior $\operatorname{diz} T$ e recebe $V$.

Brown e Gilman (1960) elencam algumas bases para o poder, dentre elas estão a idade, o sexo, os papéis institucionalizados da igreja, do estado, do exército ou os papéis dentro da família. Para ilustrar a manifestação da semântica do poder em diferentes bases, os autores trazem exemplos da história da língua, especialmente na Europa Medieval, em que os pais eram figuras do imperador e que as primeiras experiências do indivíduo de subordinação ao poder através do $V$ eram com os pais.

Considerando que a semântica do poder é não recíproca e apenas prescreve o uso entre superior e inferior, os autores estabeleceram outra semântica para o tratamento entre iguais. Nas sociedades da Europa Medieval, os pronomes de referência entre os iguais eram recíprocos, ou seja, os indivíduos davam e recebiam a mesma forma pronominal e, mesmo depois desse período, os iguais das classes altas trocavam entre si o $V$ enquanto os iguais de classes baixas trocavam o $T$.

De acordo com os autores, o fato de o $V$ ter entrado nas sociedades por meio das classes altas fez com que ele adquirisse, principalmente entre os europeus, o status de elegância e gradualmente surgiu uma conotação diferente para o $T$ e $V$ e chamou-se o $T$ de intimidade e o $V$ de formalidade. Essa nova dimensão foi chamada pelos autores de solidariedade. Todavia, como nem todas as diferenças entre as pessoas são diferenças de poder, quando as diferenças não são relacionadas ao poder, o $V$ surge em ambas as direções.

Os autores também estabelecem a solidariedade como simétrica para os relacionamentos em geral. Nessa semântica, as normas de uso são recíprocas, e o $T$ se torna mais provável à medida que a solidariedade aumenta, e o $V$ à medida que a solidariedade diminui. De acordo com os autores, essa semântica ganhou supremacia sobre a semântica do poder a partir do século XIX, e o resultado disso é um sistema unidimensional, isto é, o $T$ é recíproco de mais solidariedade e o $V$ é recíproco de menos solidariedade.

Diante do exposto, acreditamos que, ao aliarmos os métodos e as teorias descritas até aqui, poderemos analisar os dados a partir de pontos de vista diferentes, o que certamente contribuirá para que encontremos as respostas às perguntas feitas neste estudo.

\section{APRESENTAÇÃO E ANÁLISE DOS DADOS}

Ilustraremos e discutiremos aqui as respostas dadas pelos informantes à primeira pergunta do teste de percepção, que indagava o informante sobre qual forma ele costuma usar para se dirigir a um amigo ou a uma amiga? Para esta questão obtivemos as seguintes respostas. 


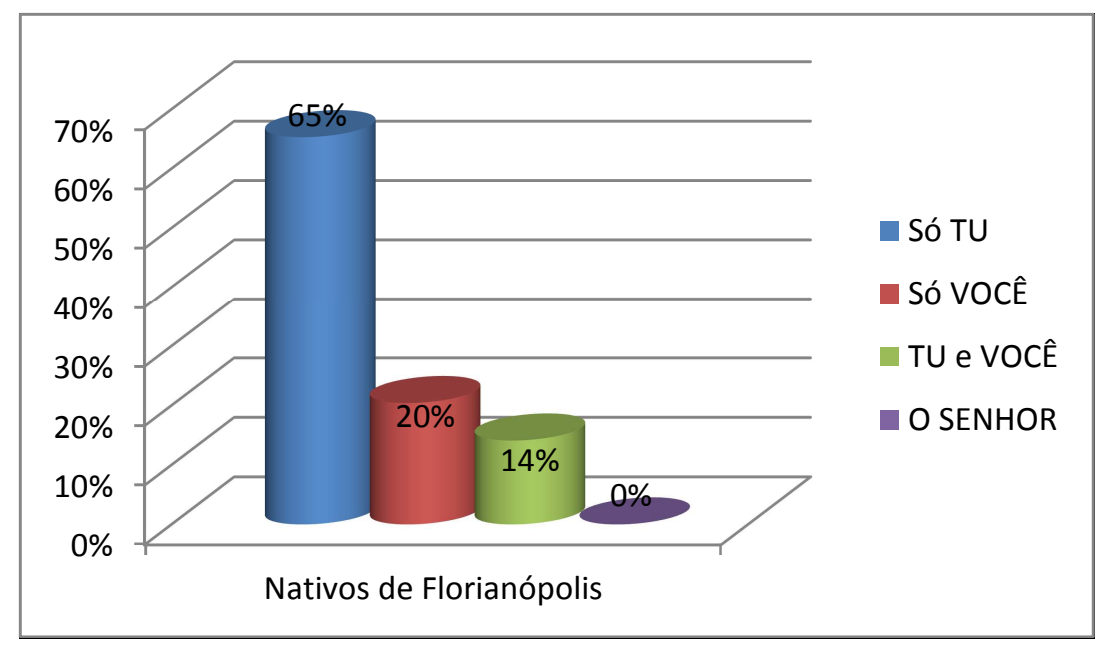

Gráfico 1: Distribuição geral das respostas dos testes referente à forma utilizada para se dirigir a um amigo

Como podemos visualizar, o uso de $t u$, em Florianópolis, é considerado o preferido pelos indivíduos para a relação de simetria e de maior intimidade, entre amigos, atingindo $65 \%$ das opiniões; $14 \%$ dos informantes afirmam que usam tanto o tu quanto o você e $20 \%$ deles afirmam que usam somente a forma você para esse tipo de relação.

É importante observar que nenhum dos informantes afirma usar a forma $o$ senhor para se dirigir a um amigo. Esse resultado confirma que o senhor e a senhora são, nas variedades europeia e americana do português, formas de respeito ou de cortesia (CUNHA e CINTRA, 1985) e, como tais, se opõem à forma tu e à forma você. Nos termos de Brown e Gilman (1960), os pronomes $o$ senhor e a senhora representariam a formalidade e, portanto, a relação de poder e, por isso, não poderiam ser usados em uma relação de simetria, ou de reciprocidade. Enquanto isso, os pronomes tu e você representariam a intimidade e, portanto, são os escolhidos para uma relação de solidariedade.

Ao observarmos o comportamento dos indivíduos separados em suas células sociais (sexo, idade e escolaridade), verificamos que somente a idade é um fator relevante na escolha da forma pronominal conforme podemos visualizar no gráfico a seguir.

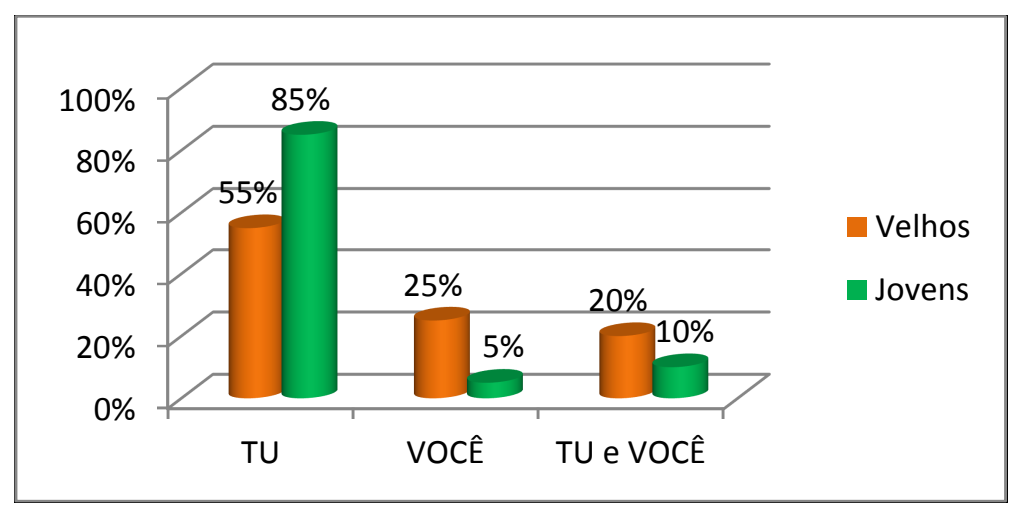

Gráfico 2: Distribuição das respostas dos testes referente à forma utilizada para se dirigir a um amigo, considerando a idade do informante 
A partir dos resultados expostos no gráfico 2, é possível notarmos que os mais jovens afirmam que usam mais $t u$ para se dirigir a um amigo ou amiga, atingindo $85 \%$ de frequência para essa forma, seguido de $5 \%$ de você e $10 \%$ de tu e você. Já os mais velhos apresentam $55 \%$ de opções pelo $t u, 25 \%$ de você e $20 \%$ de tu e você. Sendo assim, poderíamos sugerir que, para os jovens, o tu é ainda mais íntimo e, portanto, mais adequado para uma relação de simetria do que o você enquanto que, para os mais velhos, o você exerceria melhor esse papel de intimidade.

Para testarmos se o que os informantes acham que usam corresponde ao que eles realmente usam, aplicamos os testes de produção e, a partir da categorização dos dados, realizamos análises unidimensionais, considerando a alternância entre os pronomes $t u$, você e $o$ senhor, e multidimensionais, considerando somente a alternância entre os pronomes $t u$ e você. A partir dessas rodadas, o programa Goldvarb (2001) selecionou cinco grupos de fatores como relevantes para a aplicação do $t u$ em Florianópolis na seguinte ordem de relevância:

$1^{\circ}$ - tipo de relação entre os interlocutores;

$2^{\circ}$ - paralelismo sujeito e clítico;

$3^{\circ}-$ sexo;

$4^{\circ}$ - faixa etária e

$5^{\mathrm{o}}$ - paralelismo sujeito e possessivo.

Os grupos descartados foram: i) preenchimento do sujeito; ii) escolaridade e iii) paralelismo sujeito e oblíquo tônico.

Entretanto, para nos adequarmos ao espaço e aos objetivos deste estudo, discutiremos aqui apenas o grupo de fatores selecionado como o mais relevante: $O$ Tipo de Relação entre os Interlocutores.

Como vimos, o tipo de relação entre os interlocutores foi considerado pelo programa estatístico Goldvarb (2001) como a variável mais relevante para a aplicação do $t u$. Para chegarmos a tal resultado, controlamos três tipos de relação entre os interlocutores: $i$ ) relação simétrica; ii) relação assimétrica descendente e iii) relação assimétrica ascendente. Nossa hipótese era que, ao se dirigir ao inferior e aos iguais, a forma mais utilizada fosse o $t u$ e, ao se dirigir ao superior, a forma mais utilizada fosse o você ou o senhor.

A seguir, apresentamos um exemplo de comando dado para cada tipo de relação entre interlocutores controlado em nossa amostra de testes e também um exemplo de resposta dada a esses comandos.

Relação simétrica:

Imagine que você esteja convidando uma amiga ou um amigo para uma festa e quer saber se ela(ele) levará o(a) namorado(a). Então, como você diria?

( $x$ ) tu vai(s) à(na) festa de hoje com o(a)_teu_ namorado $(a)$ ?

( ) você vai à(na) festa de hoje com o(a) namorado(a)? 
( ) o(a) senhor(a) vai à(na) festa de hoje com o(a) namorado $(a)$ ? $(\mathrm{M} 3 \mathrm{CCt})^{7}$.

Relação assimétrica ascendente:

Imagine que você tenha entregado um convite para o(a) seu(sua) chefe ou professor(a) para uma festa. Você diz que ele(a) pode levar acompanhante e então pede confirmação. Então, como você diria?

( ) tu vai(s) à/na festa de hoje com esposo $(a)$ ?

( ) você vai à/na festa de hoje com $\operatorname{esposo}(a)$ ?

( $x$ ) ola senhor(a) vai à/na festa de hoje com seu/sua $\operatorname{esposo}(a) ?(\mathrm{~F} 3 \mathrm{CCt})^{8}$.

Relação assimétrica descendente:

Imagine que você tenha um(a) empregado(a) e que o(a) tenha convidado para uma festa. Você diz que ele(a) pode levar acompanhante e então pede confirmação. Como você diria?

( $x$ ) tu vai(s) à/na festa de hoje lá em minha casa com o(a) teu/tua namorado(a)/esposo(a)?

( ) você vai à/na festa de hoje lá em minha casa com o(a) namorado(a)/esposo(a)?

( ) o(a) senhor(a) vai à/na festa de hoje lá em minha casa com o(a) namorado(a)/esposo $(a)$ ? (F3CCt $)^{9}$.

Vejamos os resultados das rodadas estatísticas na tabela a seguir.

\begin{tabular}{c|c|c}
\hline $\begin{array}{c}\text { Tipo de relação entre } \\
\text { os interlocutores }\end{array}$ & $\begin{array}{c}\text { Apl./Total = } \\
\%\end{array}$ & Peso relativo \\
\hline Relação simétrica & $86 / 122=70 \%$ & 0,63 \\
\hline $\begin{array}{c}\text { Relação assimétrica } \\
\text { ascendente }\end{array}$ & $32 / 139=23 \%$ & 0,25 \\
\hline $\begin{array}{c}\text { Relação assimétrica } \\
\text { descendente }\end{array}$ & $27 / 46=58 \%$ & 0,63 \\
\hline TOTAL & $145 / 307=$ & \\
$47 \%$ & \\
\hline
\end{tabular}

Tabela 1: Uso de $t u$ em relação ao tipo de relação entre os interlocutores

\footnotetext{
${ }^{7} \mathrm{M}=$ masculino, 3 = mais escolaridade, $\mathrm{C}=$ mais jovem, $\mathrm{C}=$ localidade (centro), $\mathrm{t}=$ informante dos testes).

${ }^{8} \mathrm{~F}=$ feminino, $3=$ mais escolaridade, $\mathrm{C}=$ mais jovem, $\mathrm{C}=$ localidade $($ centro $), \mathrm{t}=$ informante dos testes).

${ }^{9} \mathrm{~F}=$ feminino, 3 = mais escolaridade, $\mathrm{C}=$ mais jovem, $\mathrm{C}=$ localidade $($ centro $), \mathrm{t}=$ informante dos testes).
} 
Como podemos verificar na tabela 1 , a relação simétrica e a relação assimétrica descendente são as que mais favorecem o uso de $t u$, apresentando 0,63 de peso relativo nas duas relações, embora as frequências tenham sido um pouco diferentes, pois temos $70 \%$ de frequência nas relações simétricas e 58\% nas relações assimétricas descendentes. As relações assimétricas ascendentes apresentam-se como sendo as mais desfavorecedoras do uso de $t u$, com 0,25 de peso relativo.

Recuperando os preceitos de Brown e Gilman (1960), vemos que uma pessoa tem poder sobre outra conforme o grau em que ela é capaz de controlar o comportamento da outra e, portanto, o superior diz $T$ e recebe $V$. Isso está nitidamente representado na tabela 1 , uma vez que a relação assimétrica descendente é uma das que mais favorecem o uso de $t u(0,63)$ enquanto a relação assimétrica ascendente é a que menos favorece o uso de $t u(0,25)$, ou seja, esses resultados atestam que o superior diz $T(t u)$ para o subalterno e recebe deste um $V$ ( $o$ senhor ou você). Sendo assim, evidencia-se que o poder é não recíproco.

Por outro lado, a solidariedade pode ser observada na tabela 1 a partir das relações simétricas que também favorecem o uso de $t u(0,63)$ para os relacionamentos entre iguais. Portanto, o $T(t u)$ é recíproco de mais solidariedade, pois o indivíduo diz $T(t u)$ e recebe $T(t u)$ do seu interlocutor.

Ao observarmos a distribuição das formas tu, você e $o$ senhor nos três tipos de relação, vemos o seguinte resultado.

\begin{tabular}{c|c|c|c}
\hline Tipo de relação & $\boldsymbol{T u}$ & Você & O senhor \\
\hline Simétrica & $86 / 122=70 \%$ & $36 / 122=29 \%$ & 0 \\
\hline Assimétrica ascendente & $32 / 139=23 \%$ & $51 / 139=36 \%$ & $56 / 139=40 \%$ \\
\hline Assimétricadescentente & $27 / 46=58 \%$ & $13 / 46=28 \%$ & $6 / 46=13 \%$ \\
\hline TOTAL & $\mathbf{1 4 5 / 3 0 7 = 4 7 \%}$ & $\mathbf{1 0 0 / 3 0 7 = 3 2 \%}$ & $\mathbf{6 2 / 3 0 7 = 2 0 \%}$ \\
\hline
\end{tabular}

Tabela 2: Uso de $t u$, você e $o$ senhor em relação ao tipo de relação entre os interlocutores

Como vemos na tabela 2, o pronome $t u$ é o preferido pelos informantes para estabelecer diálogo em relações de simetria entre os interlocutores alcançando $70 \%$ de frequência. $\mathrm{O}$ pronome você é o segundo mais utilizado para esse tipo de relação alcançando $29 \%$ de frequência. Entretanto, o pronome $o$ senhor nunca é usado para a relação entre iguais, porém, ele é o preferido para as relações assimétricas ascendentes (de inferior para superior), alcançando $40 \%$ de frequência seguido pelo você, com $36 \%$ de frequência e pelo $t u$, com apenas $23 \%$.

Para a relação assimétrica descendente (de superior para inferior), o tu também é o preferido pela maioria dos informantes, alcançando $58 \%$ de frequência, seguido pelo você, com $28 \%$, e pelo o senhor, com apenas $13 \%$.

Diante do exposto, podemos sugerir que o você, em nossa amostra, funciona como um "coringa" no tratamento, pois pode servir tanto para relações simétricas quanto para relações assimétricas descendentes e ascendentes, ou seja, ele serviria tanto para relações de poder $V$ quanto para relações de solidariedade $\mathrm{V}$, dependendo apenas da escolha do indivíduo. 


\section{CONSIDERAÇÕES FINAIS}

Considerando que o objetivo deste estudo era verificar, a partir de testes de percepção linguística, qual o pronome de segunda pessoa que os florianopolitanos afirmam usar em situações de simetria - na sua relação com os amigos, irmãos, pessoas mais íntimas etc.- e quais fatores sociais estão envolvidos nessa escolha e, ao mesmo tempo, a partir de testes de produção linguística, averiguar se os dados empíricos vão ao encontro da percepção que os sujeitos têm acerca dos seus próprios usos das formas pronominais de segunda pessoa do discurso, podemos afirmar que, de modo geral, os florianopolitanos usam majoritariamente o $t u$, seguido por um baixo percentual de você e por um baixo percentual de uso alternado das duas formas (tu e você) nas relações simétricas. Dito de outra forma, podemos assegurar que o tipo de relação entre os interlocutores é relevante para a escolha dos pronomes de segunda pessoa, pois, para dirigir-se ao inferior, a forma mais utilizada pelo superior é $t u$, o que indica poder, enquanto que, na relação entre iguais, a forma mais utilizada é a solidária tu e, no caso de inferiores se dirigindo aos superiores, a forma mais utilizada é o senhor, seguida de você indicando respeito e formalidade.

Além disso, podemos afirmar que todos os resultados dos testes de percepção linguística corroboram os resultados dos testes de produção linguística (embora os percentuais sejam um pouco diferentes), o que nos leva a concluir que os falantes têm um certo grau de consciência sobre as escolhas que fazem na língua, no que se refere aos pronomes de segunda pessoa.

Por fim, esperamos que este trabalho contribua, de alguma forma, com todos aqueles que se interessam por conhecer um pouco mais do português falado em Florianópolis - SC, especialmente pelas formas pronominais utilizadas para se dirigir ao interlocutor. Acreditamos que é preciso reconhecer não só as variedades do português brasileiro como também a visão dos falantes sobre a sua própria língua para que possamos desconstruir os preconceitos linguísticos existentes em nossa sociedade e evitar que outros sejam ensinados ou produzidos nas escolas.

\section{REFERÊNCIAS}

ARDUIN, J. A variação dos pronomes possessivos de segunda pessoa do singular teu/seu na região sul do Brasil. Dissertação de Mestrado. Universidade Federal de Santa Catarina. Florianópolis, 2005.

BROWN, R.; GILMAN, A. The pronouns of Power and solidarity. In: PAULSTON, C. B.; TUCKER, G. R. (Ed.). Sociolinguistics: The essencial readings. United Kingdom: Blackwell, p. 156-176, 2003 [1960].

CHAMBERS, J. K. Sociolinguistic theory - linguistic variation and its social significance. Oxford UK/Cambridge USA: Blackwell, 1995.

COELHO, I. L.; GÖRSKI, E. M. A variação no uso dos pronomes tu e você em Santa Catarina. In: LOPES, C.; REBOLLO, L. (orgs.) Formas de tratamento em Português e Espanhol: variação, mudança e funções conversacionais. Rio de Janeiro: 2011.

CUNHA, C. e CINTRA, L. F. L. Nova Gramática do Português Contemporâneo. Rio de Janeiro: Nova Fronteira, 1985.

LABOV, W. Principle soflinguistic change: internal factors. Oxford: Blackwel, 1994. 
LABOV, W.YAEGER, M. e STEINER, R.A quantitative study of sound change in progress. Report on National Science Foundation Contract GS-3287. Philadelphia: U.S. Regional Survey, 1972.

LEÃO, P. B. Variação de "tu" e "você" no português falado no Sul do Brasil. Disponível em: file:///Ol/Homepage/livro2/artigo_paula.htm (1of 8). Acesso em 18/11/2003.

LOREGIAN-PENKAL, L. Re(análise) da referência de segunda pessoa na fala da Região sul. Tese de Doutorado. Universidade Federal do Paraná. Curitiba, 2004.

MENON, O. P. S. Pronome de Segunda pessoa no Sul do Brasil: tu/ você/ o senhor em Vinhas da Ira. Letras de Hoje, Porto Alegre, v. 35, n. 1, p. 121-163, mar., 2000.

MOLLICA, M. C. Como o brasileiro fala, percebe e avalia alguns padrões linguísticos. In: HEYE, J. (Org.). Flores verbais, Rio de Janeiro: Editora Nova Fronteira. p. 121-129, 1995.

NUNES de SOUZA, C.. Poder e solidariedade no teatro florianopolitano dos séculos XIX e XX: uma análise sociolinguística das formas de tratamento. Dissertação de Mestrado. Universidade Federal de Santa Catarina. Florianópolis, 2011.

RAMOS, M. P. B. Formas de tratamento no falar de Florianópolis, Curso de Pós-graduação em Linguística. Dissertação de Mestrado. Universidade Federal de Santa Catarina. Florianópolis, 1989.

ROCHA, P.G. O sistema de tratamento do português de Florianópolis: um estudo sincrônico. Tese de Doutorado. Universidade Federal de Santa Catarina. Florianópolis, 2012.

SOARES, A. S. F. Segunda e terceira pessoa - o pronome possessivo em questão: uma análise variacionista. Dissertação de Mestrado. Universidade Federal do Paraná. Curitiba, 1999.

WEINREICH, U.; LABOV, W.; HERZOG, M. Empirical foundations for a theory of language change. In: Winfred P. Lehmann \&Yakov Malkiel (eds.). Directions for Historical Linguistics. Austin: University of Texas. p.95-188, 1968.

Data de submissão: 15/05/2014

Data de aceite: 09/09/2014 